\title{
Assessment of Fusarium Head Blight Resistance in Newly Developed Recombinant Inbred Lines of Wheat
}

\author{
C.C. Dweba ${ }^{1,2}$, H. Shimelis ${ }^{1}$, T. TAPERA $^{1}$ and T.J. Tsilo ${ }^{2 *}$ \\ ${ }^{1}$ University of KwaZulu-Natal, School of Agricultural, Earth and Environmental Sciences, African Centre for \\ Crop Improvement, Private Bag X01, Scottsville, Pietermaritzburg, South Africa, 3209 \\ ${ }^{2}$ Agricultural Research Council-Small Grain Institute, Private Bag X29, Bethlehem, South Africa, 9700
}

(Received 11 September 2018; Accepted 11 January 2019;

Communicated by Á. Mesterházy)

\begin{abstract}
Fusarium head blight (FHB) is an important disease of wheat causing significant yield and quality losses globally. Breeding for host plant resistance is an economic approach to FHB control and management. The aim of this study was to identify potential sources of resistance from newly developed recombinant inbred lines (RILs) of wheat. A total of 778 RILs were developed through a bi-parental mating design followed by continuous selfing and selection. The RILs along with their eight parental lines (Baviaans, Buffels, Duzi, \#910, \#936, \#937, \#942 and \#1036) and FHB resistant check cultivar 'Sumai 3' and susceptible check 'SST 806' were field evaluated across four environments in South Africa. Fusarium graminearum isolates were artificially inoculated to initiate infection and disease development. The percentage of wheat spikes showing FHB symptoms were scored. The research identified six percent of the RILs with disease resistance. Heritability for FHB resistance was the highest $(64 \%)$ indicating the possibility of achieving higher selection gains for FHB resistance across the selected environments. The following five RILs were identified as potential sources of resistance: 681 (Buffels/1036-71), 134 (Duzi/910-8), 22 (Baviaans/910-22), 717 (Baviaans/937-8) and 133 (Duzi/910-7) with mean FHB scores of $6.8 \%, 7.8 \%, 9.5 \%, 9.8 \%$ and $10 \%$, respectively. The selected lines expressed comparatively similar levels of resistance compared with that of Sumai 3. The identified RILs are useful genetic resources for resistance breeding against FHB disease of wheat. Since the presence of the F. graminearum is associated with deoxynivalenol (DON) accumulation, the DON levels amongst the selected lines should be determined to ensure the release of improved wheat cultivars with reduced levels of DON accumulation.
\end{abstract}

Keywords: Fusarium head blight, phenotype, resistance reaction, SSR markers, wheat

\section{Introduction}

Fusarium head blight caused by a fungal pathogen Fusarium is a devastating disease of wheat, maize, rice, rye, triticale, oats, barley and some grasses globally. Though the disease is caused by several Fusarium species, F. graminearum is the most dominant pathogenic fungi affecting wheat production, productivity and quality. The disease causes considerable wheat yield and quality losses in all wheat growing regions in South Africa but 
most notably on irrigated wheat. The Fusarium species are potent producers of mycotoxins including zearalenone (ZON) and type B trichothecenes, deoxynivalenol (DON) (or vomitoxin) and nivalenol (NIV) (Bottalico and Perrone 2002). Fusarium graminearum has been reported to cause serious type A trichothecene mycotoxins in North America (e.g. NX-2 and NX-3), that poses new additional health risks (Varga et al. 2015). These mycotoxins cause food contaminations toxic to both humans and animals (Zain 2012). The mycotoxins affect livestock feed, baking and milling quality of wheat and the malting and brewing qualities of barley (Boutigny et al. 2011). The pathogen occurs mainly under humid and sub-humid conditions (Goswami and Kistler 2004). It also prefers wet and warm weather conditions and worst epidemics can occur especially when these conditions prevail during anthesis and maturity.

Globally major FHB outbreaks have been observed since the initial discovery of the disease in England in 1884 (Goswami and Kistler 2004) resulting in monetary losses of billions of dollars (Lilleboe 2011). The necrotrophic F. graminearum has been an increasingly challenging fungi with recent global epidemics reported in China, Canada, South America, United States and Europe (Goswami and Kistler 2004). Between 1993 and 2001, the United States lost an estimated US\$ 2.492 - 3.0 billion (Nganje et al. 2004; Schumann and D'Arcy 2006) to FHB. Together with chronic rot (another Fusarium symptom), FHB incurred $\$ 2.7$ billion loss in northern Great Plains and central USA due to lost productivity and grain quality (Tunali et al. 2012).

In sub-Saharan Africa, FHB outbreaks would incite detrimental economic and social effects given that wheat, barley and oats are staple cereals which are grown under lowinput production systems. Losses to FHB can reach above $50 \%$ in susceptible cultivars but yield loss can reach up to $100 \%$ under epidemic proportions (Yi et al. 2018). Given the exacerbating global warming, often accompanied by increased humidity levels and temperatures, recurrent epidemics of FHB are likely to occur (Shah et al. 2014). Therefore, effective management and control of the disease is required in order to enhance productivity of wheat and for human wellbeing.

Use of FHB resistant germplasm is an important component in the integrated management of the disease. However, breeding progress for FHB resistance has been hindered by the time and cost required and the complex inheritance of the disease to develop resistant lines. The International Centre for Maize and Wheat Improvement (CIMMYT) initiated research on FHB resistance breeding in the early 1980s and since then it created elite germplasm incorporating effective resistance genes (Osman et al. 2015). There is a need to develop regionally adapted cultivars that combine high and stable yield and quality performance with resistance to FHB and other common wheat diseases (Buerstmayr et al. 2009). Five types of FHB resistance have been reported (Mesterházy et al. 1999). These include resistance to initial infection (Type I resistance); resistance to disease spread within infected heads (Type II), resistance to DON accumulation (Type III), resistance to kernel head damage (Type IV) and tolerance (Type V). Several wheat lines with quantitative trait loci (QTLs) linked with FHB resistance were identified. These included Frontana (Bai and Shaner 2004) possessing Type I resistance located on chromosome 5AS; Wangshuibai with Type I and Type II resistance on 3BS (Lin et al. 2006); Sumai 3 and its 
derivatives with Type II resistance (Bai and Shaner 2004); CM-82036 (Sumai 3/Thornbird) with Type I and Type II resistance (Buerstmayt et al. 2003, 2009; Wilde et al. 2007) and CIMMYT derived line Shanghai-3/Catbird (Lu et al. 2013). Type I and Type II resistance confer a relatively durable FHB resistance (Anderson et al. 2001; Buerstmayr et al. 2002, 2003, 2009; Mesterházy et al. 2007), and may reduce DON accumulation. However, Szabó-Hevér et al. (2014) reported that several QTLs conditioning FHB and Fusarium Kernel Damage (FDK) resistance showed non-significant effect on DON content (Szabó-Hevér et al. 2014). The Chinese wheat cultivar 'Sumai 3' is known to have the most heritable and stable resistance across environments (Rudd et al. 2001). Sumai 3 is highly resistant and extensively used in both spring and winter wheat breeding programs globally (Niwa et al. 2014). Some genotypes reportedly had overproduction of DON albeit their high level of FHB resistance (Szabó-Hevér et al. 2014). This necessitates detailed investigation on the correlation between FHB resistance and DON accumulation.

Availability of efficient screening methodologies, proper selection environment, source and type of resistance, and the nature of the pathogen and its virulence pattern are the main determinants of a resistance breeding program (Singh and Rajaram 2015). The most common screening technique to select genotypes with FHB resistance involves inoculation of test materials during the anthesis stage under conducive environmental conditions. High temperatures $\left(25\right.$ to $\left.28{ }^{\circ} \mathrm{C}\right)$ and high relative humidity $(>90 \%)$ are ideal conditions to initiate FHB infection and disease development (Rudd et al. 2001; Goswami and Kistler 2004). In an attempt to develop FHB resistant wheat cultivars, a pre-breeding research project was initiated at the Agricultural Research Council-Small Grain Institute (ARC-SGI) in South Africa in collaboration with global and regional wheat researchers. The program developed 778 new recombinant inbred lines (RILs) through designed crosses and continuous selfing and selection. The objective of this study was to assess the response of the newly developed recombinant inbred lines across representative growing environments and to select FHB resistant lines for effective breeding.

\section{Materials and Methods}

\section{Plant materials and crosses}

The genetic materials used in the trial are indicated in Table 1. The study used five new sources of FHB resistant wheat lines obtained from CIMMYT to recombine their genes into local and commercial cultivars. The source parental lines and their pedigrees are designated as follows: BCHA/MILAN, INIA CANURE/INIA TIJERETA (no. 36 of the 9th SRSN) and INIACABURE/LAJ3153 (no. 37 of the 9th SRSN), KAKATSI and IVAN/6/SABUF/5/SCN/4/RABI/GS/CRA/3/AE.SQUARROSA (190). Hereafter, the five donor lines are referred to as \#910; \#936; \#937; \#942 and \#1036, in that order. The lines were crossed with three South African spring wheat cultivars (Baviaans, Buffels and Duzi) known for their wide adaptation under local conditions, especially under irrigation where FHB is predominant. The source lines and local parent materials were crossed using a bi-parental mating scheme providing 14 populations except the cross of Buffels and 
\#936. From the 14 populations 778 RILs were developed through the single seed descent selection method. Progenies were continuously selfed and advanced to $\mathrm{F}_{6: 7}$, providing homozygous RILs used in the present study.

Table 1. Number of RILs of wheat developed in each population for the study

\begin{tabular}{|l|c|l|c|}
\hline \multicolumn{1}{|c|}{ Cross } & No. of RILs developed $^{\mathrm{a}}$ & \multicolumn{1}{c|}{ Cross } & No. of RILs developed $^{\mathrm{a}}$ \\
\hline Baviaans/\#910 & 70 & Buffels/\#942 & 30 \\
\hline Baviaans/\#936 & 12 & Buffels/\#1036 & 50 \\
\hline Baviaans/\#937 & 66 & Duzi/\#910 & 82 \\
\hline Baviaans/\#942 & 67 & Duzi/\#936 & 56 \\
\hline Baviaans/\#1036 & 56 & Duzi/\#937 & 72 \\
\hline Buffels/\#910 & 33 & Duzi/\#942 & 41 \\
\hline Buffels/\#937 & 43 & Duzi/\#1036 & 778 \\
\hline Total & \multicolumn{3}{|l}{} \\
\hline
\end{tabular}

${ }^{\mathrm{a}} \mathrm{RILs}=$ Recombinant inbred lines.

\section{Study sites and field establishment}

The 778 RILs, one resistant check cv. Sumai 3, one susceptible check cv. SST 806 and eight parental lines Baviaans, Buffels, Duzi, \#910, \#936, \#937, \#942 and \#1036 were evaluated across four environments in South Africa. Briefly, the environments were as follows: Agricultural Research Council (ARC), Bethlehem Research Station situated in the Free State Province during 2014 and 2015 (hereafter denoted as Beth 2014 and Beth 2015, in that order) and Cedara Research Station located in KwaZulu-Natal Province during 2014 and 2015 (abbreviated as Ced 2014 and Ced 2015, respectively). These provided four testing environments and designated as Beth 2014; Beth 2015; Ced 2014 and Ced 2015.

The test genotypes were planted in hill plots and grown under irrigation using an augmented block design. At each environment, six blocks were established, and 130 RILs and eight parents were randomly assigned per block. After every 10 RILs, a resistant and susceptible check was planted. Fertilizers [3:2:1 (32) + 0.5\% Zn; with N 160 g/kg; P 107 $\mathrm{g} / \mathrm{kg}$; K $53 \mathrm{~g} / \mathrm{kg}$ and Zn $5 \mathrm{~g} / \mathrm{kg}$, Sasol] were applied. Pre-emergent weeds were controlled using the herbicide Roundup (Pro ${ }^{\circledR}$ Concentrate, Monsanto), while post-emergent weeds were removed manually using hand hoes. Fields were irrigated immediately after planting and fortnightly afterwards. Daily average maximum temperatures during both growing seasons ranged between $24-27^{\circ} \mathrm{C}$ and $15-26^{\circ} \mathrm{C}$ at Cedara and Bethlehem, respectively. The minimum temperatures between $12-16^{\circ} \mathrm{C}$ and $0-12{ }^{\circ} \mathrm{C}$ were recorded across the testing areas, in that order. Average humidity for the growing seasons at Bethlehem and Cedara ranged between $17-90 \%$ and $74-94 \%$, respectively. 


\section{Inoculum preparation and inoculation}

Five isolates of F. graminearum (F7.3, N22D, B7.3, F1.01 and B3.8) were used for the study. Isolates were obtained from the plant protection laboratory of the ARC-SGI. Isolates were originally collected from wheat fields situated at Prieska area, in the Northern Cape Province of South Africa. The isolates were selected for their known high virulence and spore production. These isolates were grown on Potato Dextrose Agar (PDA) for 14-21 days and liquid inoculum was prepared following the method described by DillMacky (2003) with slight modification, where Mung-bean agar was used as a substrate to grow the cultures. Upon production of fresh sufficient spores, aliquots of the liquid inoculum were prepared and kept at $-4{ }^{\circ} \mathrm{C}$ prior to inoculations. The inoculum from various F. graminearum isolates was mixed prior to field inoculations. Inoculum, with a standardized spore count of $1 \times 10^{5}$ macroconidia $\mathrm{ml}^{-1}$, was applied to the spikes at the onset of anthesis using a pressurized $16 \mathrm{~L}$ capacity Kaufmann knapsack sprayer (Kaufmann, Kaufumann), allowing for individual inoculation of plots. Inoculated spikes were kept under humid conditions by covering the inoculated plants with a plastic bag overnight to ensure optimum infection and disease development. A second inoculation was applied two days after initial inoculation to minimize disease escape and to facilitate infection. Colonized grain inoculation method was carried out at the Cedara site. The site has significantly higher humidity level, allowing infection and disease development. Fuentes et al. (2005) suggested that both the colonized-grain and conidial-spray inoculation methods provided disease levels that are appropriate to differentiate resistant and susceptible cultivars. Briefly, dried maize (Zea mays L.) kernels prepared in the form of samp were autoclaved twice over two days and subsequently inoculated with $F$. graminearum following the Dill-Macky (2003) protocol. Fusarium graminearum colonized grain was incubated at $30{ }^{\circ} \mathrm{C}$ for approximately $3-4$ weeks to promote infection. The infected grain was then dried and stored at room temperature prior to use. The Cedara field was inoculated uniformly by spreading the $F$. graminearum colonized grains on the soil surface approximately 6 weeks post planting.

\section{Data collection and analysis}

The response of sampled wheat lines against FHB were evaluated using a rating scale suggested by Engle et al. (2003) 28 days post inoculation. FHB severity (0 to 100\%) was recorded as the proportion of the heads showing FHB symptoms per RIL. FHB severity was associated with additional symptoms including pink to salmon-orange spore mass production on the infected spikelets and the dark brown or purple discoloration on the stem immediately below the head. To facilitate disease rating, resistant and susceptible checks were planted after every 10-12 RILs in the field. Four of the 778 RILs failed to germinate across all the four environments and therefore data was collected from 774 RILs. Weather conditions were recorded for the four environments during the study period (Table $\mathrm{S} 1 *$ ).

*Further details about the Electronic Supplementary Material (ESM) can be found at the end of the article. 
Disease severity data was subjected to analysis of variance (ANOVA) using the general linear model of the augmented design procedure (PROC GLM) in SAS (version 9.1; SAS Institute In., Cary NC), with genotype and environment being random factors. Mean comparisons were performed using the least significant difference (LSD) test procedure at $5 \%$ level of significance. Maximum, minimum, range, coefficient of variation (CV) expressed in percent (\%) were calculated on disease severity. Correlation analysis was performed and Pearson's correlation coefficients calculated to describe the association of disease severity among the four environments. Variance components (genotype and genotype-environment interactions) were used to estimate the broad-sense heritability and to explain the total proportion of the phenotypic variance that is attributable to the genetic variance based on diseases severity.

The broad sense heritability estimate was calculated using the following formula: $\mathrm{h}^{2}{ }_{\mathrm{B}}=1-\mathrm{MS}_{\mathrm{ge}} / \mathrm{MS}_{\mathrm{g}}$, where $\mathrm{h}_{\mathrm{B}}^{2}=$ heritability in the broad sense; MSge = Mean Square of genotype environment interaction; $\mathrm{MSg}=$ Mean square of genotype.

\section{Results}

\section{Analysis of variance of FHB severity}

Two separate analysis of variance were conducted and shown in Table 2. The first involved the RILs across the four testing environments, and the second considered the 10 check entries ( 8 parents, 1 susceptible and 1 resistant entries) only. This allowed analysis of the unreplicated RILs within the environment (Federer 1961). Both analyses revealed the presence of highly significant $(\mathrm{P}<0.01)$ effect of genotypes, environment $(\mathrm{E})$ and genotype by environment interaction $(\mathrm{G} \times \mathrm{E})$ on FHB severity implying differential performance of genotypes across environments. There existed significant differences among checks $(\mathrm{P}<0.001)$ across the four environments. Heritability for FHB resistance value

Table 2. Analysis of variance of FHB severity involving 774 RILs, eight parents and two check wheat lines evaluated across four testing environments

\begin{tabular}{|c|c|c|c|}
\hline Source of variation & df & Mean Square & F value \\
\hline \multicolumn{4}{|l|}{ RILs } \\
\hline Genotypes & 773 & 1061.00 & $2.78 * *$ \\
\hline Environments & 3 & 237923.00 & $622.55^{* *}$ \\
\hline Genotypes $\times$ environments & 1850 & 382.20 & $8.82 * *$ \\
\hline \multicolumn{4}{|l|}{ Checks } \\
\hline Genotypes & 9 & 4272.82 & $98.67 * *$ \\
\hline Error & 81 & 43.31 & \\
\hline \multicolumn{3}{|c|}{$\begin{array}{l}\operatorname{Var}(\text { checks })=1875.97 \\
\operatorname{Var}(\text { checks } \times \text { environments })=57.27\end{array}$} & \\
\hline $\operatorname{Var}($ environments $)=29.21$ & & $\operatorname{Var}($ error $)=236.95$ & \\
\hline
\end{tabular}

$\mathrm{CV}(\%)=24.77 ; \operatorname{LSD}(5 \%)=3.46 ; * * * \mathrm{P}<0.001 ; * * \mathrm{P}<0.01 ; * \mathrm{P}<0.05$ df degrees of freedom. 
was $64 \%$, indicating the possibility of achieving high selection gains in the tested population and environments. The coefficient of variation was $24.77 \%$, suggesting considerable variation of the test lines for FHB disease reaction.

\section{Field response of RILs, parents and checks for FHB resistance}

Results suggested differential responses of test genotypes for FHB severity (Table 3; Table 4). About $6 \%$ of RILs had a FHB severity score of less than $20 \%$. FHB severity score of $<20 \%$ is regarded as a relatively resistant reaction type. The FHB reaction of the resistant check varied from $1 \%$ to $15 \%$ across the four environments, therefore, some of the newly developed RILs possessed comparatively higher levels of FHB resistance, which were selected for breeding.

The mean FHB readings at Bethlehem were at $13.23 \%$ and $13.56 \%$ in 2014 and 2015 , respectively (Table 3 ). This was a relatively low rating compared to that of Cedara that provided mean scores of $32.25 \%$ and $31.61 \%$ during 2014 and 2015, in that order. Approximately $10 \%$ of the RILs (75) were selected as the best performers showing the least FHB severity scores. Table 3 presented the field response of the $10 \%$ best performing RILs, parents and checks across the four testing environments. FHB severity scores of the RILs showed marked variation across all testing sites. FHB severity scores of the selected RILs varied from $6.75 \%$ to $43.25 \%$ with a mean of $46.65 \%$.

The following five RILs: (Buffels/1036-71), 134 (Duzi/910-8), 22 (Baviaans/910-22), 717 (Baviaans/937-8) and 133 (Duzi/910-7) had FHB severity scores of $\leq 10 \%$ across the four environments (Table 3). The resistant check, Sumai 3, had mean FHB severity scores of $5.96 \%, 5.46 \%, 10.43 \%$ and $8.28 \%$ at Beth 2014, Beth 2015, Ced 2014 and Ced 2015, respectively. Therefore, the five candidate RILs had relatively good level of FHB resistance compared to the check. These lines are valuable genetic resources for further breeding or large-scale production under FHB prone environments in South Africa or related agro-ecologies. The lowest FHB scoring environments were Beth 2014 and Beth 2015 for both the elite lines as well as the resistant checks, while infection levels at Cedara were relatively higher. The Cedara site is a hotspot area of various plant diseases in South Africa. A recent study revealed a much higher disease pressure of leaf rust in Cedara, compared to other testing sites across the country (Figlan et al. 2017).

The parental lines showed significant variability for FHB reaction across the testing sites. The parents, \#1036, \#937 and \#910 had the lowest FHB scores with mean FHB reading of $17.8 \%, 30.2 \%$ and $35.8 \%$, respectively (Table 3 ). The parents, \#936 and \#942 had mean FHB scores of $44.1 \%$ and $61.3 \%$, respectively. As expected, South African wheat cultivars Baviaans, Buffels and Duzi, had relatively high mean severity scores of 44.83\%, 51.4\% and 55.7\%, respectively (Table 3).

Some 29 RILs that were relatively FHB resistant in this study had the donor parent \#910 in their parentage. Whereas, 26 RILs had the donor parent \#1036, and 10 RILs had the parent \#937 in their pedigree. About 8\% and 5\% of the resistant RILs had donor parents \#942 and \#936, respectively. The significant occurrence of the donor parents \#910, \#1036 and \#937 in the pedigree of the promising RILs selected in this study highlights 
Table 3. Field severity (\%) of FHB of the best $10 \%$ selected RILs and eight parents and two checks of bread wheat genotypes evaluated across four testing environments in South Africa

\begin{tabular}{|c|c|c|c|c|c|c|}
\hline \multirow{2}{*}{ Line } & \multirow{2}{*}{ RIL } & \multicolumn{2}{|c|}{ Beth } & \multicolumn{2}{|c|}{ Ced } & \multirow{2}{*}{ Mean } \\
\hline & & 2014 & 2015 & 2014 & 2015 & \\
\hline 22 & Bav/910-22 & 8.00 & 8.00 & 10.00 & 12.00 & 9.50 \\
\hline 27 & Bav/910-27 & 2.00 & 11.00 & 55.00 & 35.00 & 25.75 \\
\hline 43 & Bav/910-43 & 4.00 & 13.00 & 23.00 & 28.00 & 17.00 \\
\hline 47 & Bav/910-47 & 10.00 & 15.00 & 60.00 & 60.00 & 36.25 \\
\hline 59 & Bav/910-59 & 6.00 & 15.00 & 18.00 & 62.00 & 25.25 \\
\hline 60 & Bav/910-60 & 5.00 & 16.00 & 26.00 & 35.00 & 20.50 \\
\hline 76 & Bav/1036-6 & 8.00 & 2.00 & 59.00 & 8.00 & 19.25 \\
\hline 89 & Bav/1036-19 & 12.00 & 7.00 & 49.00 & 59.00 & 31.75 \\
\hline 97 & Bav/1036-27 & 12.00 & 12.00 & 23.00 & 1.00 & 12.00 \\
\hline 100 & Bav/1036-30 & 17.00 & 20.00 & 60.00 & 71.00 & 42.00 \\
\hline 114 & Bav/1036-44 & 25.00 & 18.00 & 60.00 & 70.00 & 43.25 \\
\hline 127 & \begin{tabular}{|l|} 
Duzi/910-1 \\
\end{tabular} & 6.00 & 7.00 & 10.00 & 28.00 & 12.75 \\
\hline 128 & Duzi/910-2 & 10.00 & 20.00 & 10.00 & 20.00 & 15.00 \\
\hline 129 & \begin{tabular}{|l} 
Duzi/910-3 \\
\end{tabular} & 30.00 & 22.00 & 22.00 & 20.00 & 23.50 \\
\hline 130 & \begin{tabular}{|l|} 
Duzi/910-4 \\
\end{tabular} & 6.00 & 5.00 & 60.00 & 50.00 & 30.25 \\
\hline 133 & Duzi/910-7 & 2.00 & 5.00 & 15.00 & 18.00 & 10.00 \\
\hline 134 & \begin{tabular}{|l} 
Duzi/910-8 \\
\end{tabular} & 5.00 & 5.00 & 10.00 & 11.00 & 7.75 \\
\hline 135 & Duzi/910-9 & 7.00 & 12.00 & 34.00 & 38.00 & 22.75 \\
\hline 137 & Duzi/910-11 & 28.00 & 10.00 & 20.00 & 12.00 & 17.50 \\
\hline 138 & Duzi/910-12 & 20.00 & 30.00 & 28.00 & 32.00 & 27.50 \\
\hline 144 & Duzi/910-18 & 2.00 & 8.00 & 50.00 & 68.00 & 32.00 \\
\hline 150 & Duzi/910-24 & 5.00 & 5.00 & 19.00 & 15.00 & 11.00 \\
\hline 154 & Duzi/910-28 & 7.00 & 15.00 & 28.00 & 32.00 & 20.50 \\
\hline 161 & Duzi/910-35 & 12.00 & 28.00 & 15.00 & 25.00 & 20.00 \\
\hline 163 & Duzi/910-37 & 6.00 & 15.00 & 8.00 & 15.00 & 11.00 \\
\hline 164 & Duzi/910-38 & 12.00 & 17.00 & 48.00 & 52.00 & 32.25 \\
\hline 165 & Duzi/910-40 & 3.00 & 4.00 & 19.00 & 20.00 & 11.50 \\
\hline 167 & Duzi/910-41 & 9.00 & 35.00 & 15.00 & 30.00 & 22.25 \\
\hline 169 & Duzi/910-43 & 18.00 & 11.00 & 15.00 & 18.00 & 15.50 \\
\hline 170 & Duzi/910-44 & 23.00 & 5.00 & 60.00 & 52.00 & 35.00 \\
\hline 175 & Duzi/910-49 & 12.00 & 18.00 & 19.00 & 20.00 & 17.25 \\
\hline 210 & Duzi/936-22 & 10.00 & 5.00 & 35.00 & 39.00 & 22.25 \\
\hline 212 & Duzi/936-24 & 3.00 & 12.00 & 60.00 & 69.00 & 36.00 \\
\hline 240 & Duzi/936-52 & 6.00 & 5.00 & 35.00 & 28.00 & 18.50 \\
\hline 268 & Duzi/936-80 & 19.00 & 10.00 & 38.00 & 35.00 & 25.50 \\
\hline 275 & Bav/942-6 & 23.00 & 21.00 & 30.00 & 40.00 & 28.50 \\
\hline 277 & $\mathrm{Bav} / 942-8$ & 15.00 & 6.00 & 40.00 & 42.00 & 25.75 \\
\hline 285 & Bav/942-16 & 6.00 & 5.00 & 40.00 & 40.00 & 22.75 \\
\hline
\end{tabular}


Table 3 (cont.)

\begin{tabular}{|c|c|c|c|c|c|c|}
\hline \multirow{2}{*}{ Line } & \multirow{2}{*}{ RIL } & \multicolumn{2}{|c|}{ Beth } & \multicolumn{2}{|c|}{ Ced } & \multirow{2}{*}{ Mean } \\
\hline & & 2014 & 2015 & 2014 & 2015 & \\
\hline 295 & Bav/942-26 & 6.00 & 10.00 & 60.00 & 40.00 & 29.00 \\
\hline 304 & Bav/942-35 & 3.00 & 10.00 & 39.00 & 35.00 & 21.75 \\
\hline 327 & Bav/942-58 & 20.00 & 15.00 & 50.00 & 45.00 & 32.50 \\
\hline 394 & Duzi/1036-3 & 18.00 & 13.00 & 12.00 & 18.00 & 15.25 \\
\hline 398 & Duzi/1036-7 & 6.00 & 15.00 & 20.00 & 35.00 & 19.00 \\
\hline 403 & Duzi/1036-12 & 6.00 & 10.00 & 37.00 & 1.00 & 13.50 \\
\hline 407 & Duzi/1036-16 & 25.00 & 27.00 & 15.00 & 16.00 & 20.75 \\
\hline 409 & Duzi/1036-18 & 10.00 & 15.00 & 35.00 & 15.00 & 18.75 \\
\hline 410 & Duzi/1036-19 & 25.00 & 8.00 & 40.00 & 35.00 & 27.00 \\
\hline 414 & Duzi/1036-23 & 16.00 & 5.00 & 40.00 & 41.00 & 25.50 \\
\hline 424 & Duzi/1036-33 & 35.00 & 3.00 & 18.00 & 19.00 & 18.75 \\
\hline 437 & Buff/1036-5 & 11.00 & 10.00 & 48.00 & 45.00 & 28.50 \\
\hline 439 & Buff/1036-7 & 13.00 & 5.00 & 58.00 & 12.00 & 22.00 \\
\hline 451 & Buff/1036-19 & 2.00 & 5.00 & 50.00 & 55.00 & 28.00 \\
\hline 455 & Buff/1036-23 & 30.00 & 18.00 & 20.00 & 8.00 & 19.00 \\
\hline 476 & Buff/1036-44 & 18.00 & 10.00 & 30.00 & 30.00 & 22.00 \\
\hline 479 & Buff/1036-47 & 21.00 & 16.00 & 23.00 & 68.00 & 32.00 \\
\hline 487 & Buff/1036-55 & 10.00 & 25.00 & 32.00 & 30.00 & 24.25 \\
\hline 492 & Buff/1036-60 & 8.00 & 18.00 & 19.00 & 7.00 & 13.00 \\
\hline 499 & Buff/1036-67 & 30.00 & 35.00 & 30.00 & 35.00 & 32.50 \\
\hline 511 & Buff/937-12 & 25.00 & 18.00 & 55.00 & 60.00 & 39.50 \\
\hline 519 & Buff/937-20 & 25.00 & 20.00 & 45.00 & 19.00 & 27.25 \\
\hline 521 & Buff/937-22 & 17.00 & 12.00 & 25.00 & 37.00 & 22.75 \\
\hline 533 & Buff/937-34 & 23.00 & 18.00 & 26.00 & 25.00 & 17.25 \\
\hline 652 & Buff/910-8 & 9.00 & 11.00 & 58.00 & 41.00 & 29.75 \\
\hline 653 & Buff/910-9 & 24.00 & 32.00 & 30.00 & 33.00 & 29.75 \\
\hline 654 & Buff/910-10 & 5.00 & 5.00 & 32.00 & 35.00 & 19.25 \\
\hline 678 & Buff/1036-68 & 18.00 & 18.00 & 48.00 & 41.00 & 31.25 \\
\hline 681 & Buff/1036-71 & 4.00 & 10.00 & 12.00 & 1.00 & 6.75 \\
\hline 694 & Buff/1036-84 & 10.00 & 17.00 & 15.00 & 50.00 & 23.00 \\
\hline 700 & Buff/1036-90 & 12.00 & 15.00 & 32.00 & 10.00 & 17.25 \\
\hline 717 & Bav/937-8 & 5.00 & 9.00 & 10.00 & 15.00 & 9.75 \\
\hline 722 & $\mathrm{Bav} / 937-13$ & 28.00 & 15.00 & 26.00 & 27.00 & 24.00 \\
\hline 730 & Bav/937-21 & 12.00 & 10.00 & 15.00 & 20.00 & 14.25 \\
\hline 731 & Bav/937-22 & 15.00 & 13.00 & 35.00 & 28.00 & 22.75 \\
\hline 733 & Bav/937-24 & 14.00 & 15.00 & 33.00 & 10.00 & 18.00 \\
\hline 736 & Bav/937-27 & 19.00 & 27.00 & 20.00 & 19.00 & 16.50 \\
\hline
\end{tabular}




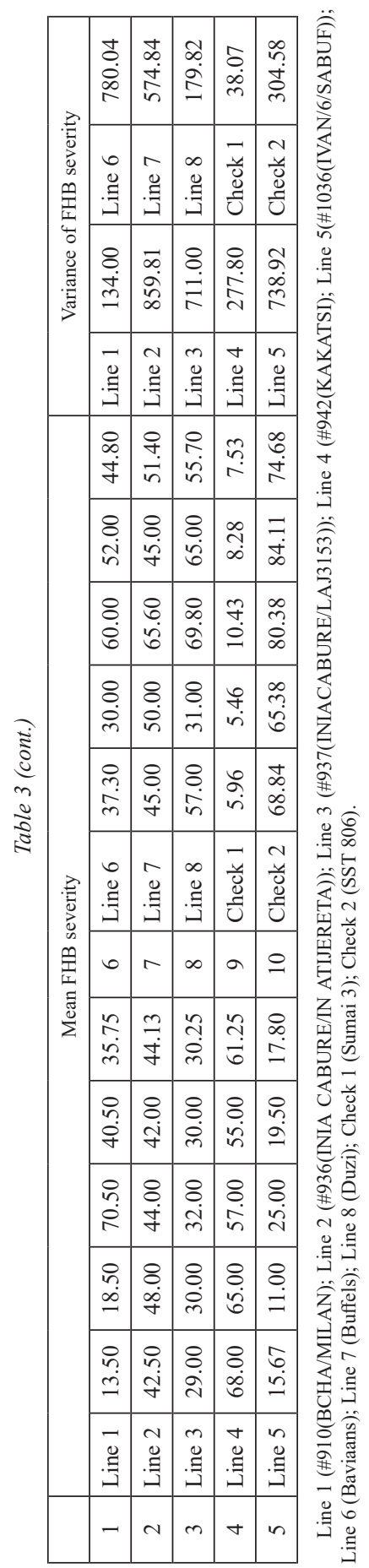


their genetic worthiness for FHB resistance breeding in wheat. The susceptible check 'SST 806' had mean FHB scores of $68.84 \%, 65.38 \%, 80.38 \%$ and $84.11 \%$ at Beth 2014, Beth 2015, Ced 2014 and Ced 2015, respectively. The following RILs had high FHB scores: 106 (Baviaans/1036-36), 367 (Duzi/937-32), 432 (Duzi/1036-41), 221 (Duzi/93633 ) and 224 (Duzi/936-36) with mean scores of $95 \%, 90 \%, 90 \%, 89 \%$ and $88.3 \%$, respectively. These ratings were comparable to the susceptible check (Table 3 ).

\section{Correlation of FHB severity across testing environments}

There were significant correlations $(\mathrm{P}<0.01)$ of FHB severity scores of genotypes across the four testing environments (Table 4). Beth 2014 and Beth 2015 had significantly higher correlation coefficient of 0.579 followed by Ced 2014 and Ced 2015 with a correlation coefficient of 0.294 . Therefore, a relatively similar pattern of FHB responses was noted on testing the genotypes across the four environments. Correlations of FHB severity between the Bethlehem and Cedara sites were relatively low but positive and significant. This was evident from the correlation coefficients recorded using 774 RILs across four testing environments. Variance due to the environments was relatively low (29.21) (Table 2). Sumai 3 had consistently low mean value (7.53) and low variance (37.08) for disease severity across the test environments (Table 3). The Cedara site had higher humidity levels (Table S1). As such, development of FHB was highly favored in this site when compared to the Bethlehem site. In addition, experimental trials at Cedara were inoculated with colonized samp kernels which resulted in a reliable disease infection. The Bethlehem site was sprayed with inoculum that had a standardized spore count of $1 \times 10^{5}$ macroconidia $\mathrm{ml}^{-1}$. Fields inoculated with the same procedure may show a stronger correlation than with the different inoculation methods. However, both inoculation methods provided disease levels that were appropriate to differentiate between resistant and susceptible genotypes. The stronger correlation values among testing environments signaled the repeatability of severity scores to reliably differentiate test genotypes. As expected, Cedara proved to be the best environment for FHB screening. This site has suitable environmental conditions conducive for initial infection and high disease development and consequently high levels of infection pressure for accurate selection of promising RILs.

Table 4. Pearson's correlation coefficients showing associations of the four testing environments for FHB severity

\begin{tabular}{|l|l|l|l|}
\hline \multicolumn{1}{|c|}{ Testing sites } & Beth 2014 & Beth 2015 & Ced 2014 \\
\hline Beth 2015 & $0.579^{* *}$ & & \\
\hline Ced 2014 & $0.189 * *$ & $0.233^{* *}$ & \\
\hline Ced 2015 & $0.184^{* *}$ & $0.193 * *$ & $0.294^{* *}$ \\
\hline
\end{tabular}




\section{Discussion}

The occurrence of mycotoxins, especially DON, ZON and NIV (Bottalico and Perrone 2002) is a threat to global food security, trade and wheat production (Misihairabgwi et al. 2017; Palacios et al. 2017a). The European Union and several other countries have instituted laws to govern different levels of mycotoxins (Shephard et al. 2009; Gelderblom et al. 2014; SAGL 2018). This research identified huge variability in terms of FHB resistance in the selected wheat genotypes. Spanic et al. (2013) and Palacious et al. (2017b) also reported considerable genetic diversity among wheat lines in Croatia and Argentina, respectively. Environmental effects play a significant role in the infection process and disease development and ultimate response of wheat genotypes to FHB. Significant $\mathrm{G} \times \mathrm{E}$ interactions also suggest that response to FHB was also a component of the environmental effect. The FHB severity reaction of genotypes varied across the test environments given the variability in environmental conditions or differences in the aggressiveness of isolates. This was the observed trends across studied experimental sites with alternating wet and warmer environments of South Africa (Goswami and Kistler 2004; Figlan et al. 2017). Cedara site had higher temperatures and humidity conditions (Table S1) compared to the Bethlehem site. These conditions favoured high levels of FHB development for efficient selection of wheat genotypes with variable levels of FHB response. These findings concurred with Osman et al. (2015) who also reported that resistance/ susceptibility is environmentally-dependent variables in FHB disease epiphytotics.

To identify promising FHB resistant genotypes successfully, effective phenotyping protocols and testing conditions are crucial (Osman et al. 2015). Populations that segregate for certain traits will often exhibit phenotypes that are on the extreme ends of the scale relative to parental lines (Rieseberg et al. 2003). This genetic phenomenon is referred to as transgressive segregation. Individuals with novel phenotypes better than the parents are often selected due to transgressive segregation for economic traits. Therefore, the RILs selected with FHB resistance or susceptibility comparatively better or worse than their respective donor parents are subject to transgressive segregation. The segregants in this population have been stabilized through continuous selection and selfing. In addition, these lines may possess additive or dominance genes contributing to the high FHB resistance which is the subject of future investigation. Overall, the best performing RILs were derivatives of the best performing parents such as \#1036, \#937 and \#910 reiterating their genetic value for breeding.

The global Fusarium Head Blight Screening Nursery (FHBSN) \{previously known as Scab Resistance Screening Nursery [SRSN] (Bekele et al. 1988)\} was established in 1985 at CIMMYT, Mexico and has since released several FHB resistant candidate wheat lines after strict field screening (He et al. 2013). This strategy has provided for identification of new resistant sources with novel resistance. Similarly, the results from this study allowed for identification of new FHB resistant genetic stocks after successful gene introgression into the South African wheat gene pool. The five best performing genotypes developed in this study are valuable for FHB resistance breeding programs or for the wheat industry in 
South Africa or similar agro-ecologies. There is limited study that reported successful selection or breeding for FHB resistance in South Africa.

The results of this study indicated the presence of considerable level of variation among the tested RILs for FHB resistance. Only $2 \%$ of the RILs had FHB scores greater than the susceptible check, while $60 \%$ of the lines scored $<50 \%$ FHB severity. The present study selected five best RILs including 681 (Buffels/1036-71), 134 (Duzi/910-8), 22 (Baviaans/910-22), 717 (Baviaans/937-8) and 133 (Duzi/910-7) with mean FHB scores of $6.8 \%, 7.8 \%, 9.5 \%, 9.8 \%$ and $10 \%$, respectively. The five RILs performed well compared with the resistant check Sumai 3 which had a mean FHB score of $7.53 \%$. The testing environment providing high level of FHB infection and development with the higher potential for FHB screening is the Cedara site, attributable to high humidity levels and temperatures compared to the Bethlehem site. The selected promising lines need further phenotyping for important agro-morphological traits and other biotic and abiotic stress tolerance. Furthermore, the selected RILs need to be genotyped to pinpoint the novel major genes or quantitative trait loci (QTL) conditioning FHB resistance for the development and deployment of elite lines with enhanced productivity. The research utilized resistant materials from the international breeding materials (CIMMYT) which has known resistance (Types I, II) levels. The observed resistance in the present study indicates the potential of developing FHB resistant cultivars for both South African niche market and other areas with similar environments. The report documents some of the results of research initiatives in South Africa aimed at improving FHB resistance in local wheat germplasm. This is one of the examples that through collaborations and use of international research platforms such as FHBSN of CIMMYT, much progress can be made in developing countries when over-coming the reproducibility of FHB resistance, which requires multiple environment testing.

\section{Acknowledgements}

We are indebted to the Agricultural Research Council-Small Grain Institute (South Africa) and the National Research Foundation of South Africa for funding the research project.

\section{References}

Anderson, J.A., Stack, R.W., Liu, S., Waldron, B.L., Fjeld, A.D., Coyne, C., Moreno-Sevilla, B., Fetch, J.M., Song, Q.J., Cregan, P.B., Frohberg, R.C. 2001. DNA markers for Fusarium head blight resistance QTLs in two wheat populations. Theor. Appl. Genet. 102(8):1164-1168.

Bai, G., Shaner, G. 2004. Management and resistance in wheat and barley to Fusarium head blight. Annu. Rev. Phytopathol. 42:135-161.

Bekele, G., Singh, R.P., Alcala, M. 1988. Results of the first international scab resistance screening nursery (SRSN) 1985-86. CIMMYT, Mexico, D.F. Mexico.

Bottalico, A., Perrone, G. 2002. Toxigenic Fusarium species and mycotoxins associated with head blight in small-grain cereals in Europe. In: Logrieco, A., Bailey, J.A., Corazza, L. and Cooke, B.M. (eds). Mycotoxins in plant disease. Springer, Dordrecht, The Netherlands. pp. 611-624. 
Boutigny, A.L., Ward, T.J., Van Coller, G.J., Flett, B., Lamprecht, S.C., O’Donnell, K., Viljoen, A. 2011. Analysis of the Fusarium graminearum species complex from wheat, barley and maize in South Africa provides evidence of species-specific differences in host preference. Fungal Genet. Biol. 48(9):914-920.

Buerstmayr, H., Ban, T., Anderson, J.A. 2009. QTL mapping and marker-assisted selection for Fusarium head blight resistance in wheat: a review. Plant Breeding 128:1-26.

Buerstmayr, H., Lemmens, M., Hartl, L., Doldi, L., Steiner, B., Stierschneider, M., Ruckenbauer, P. 2002. Molecular mapping of QTLs for Fusarium head blight resistance in spring wheat. I. Resistance to fungal spread (Type II resistance). Theor. Appl. Genet. 104(1):84-91.

Buerstmayr, H., Steiner, B., Hartl, L., Griesser, M., Angerer, N., Lengauer, D., Miedaner, T., Schneider, B., Lemmens, M. 2003. Molecular mapping of QTLs for Fusarium head blight resistance in spring wheat. II. Resistance to fungal penetration and spread. Theor. Appl. Genet. 107(3):503-508.

Dill-Macky, R. 2003. Inoculation methods and evaluation of Fusarium head blight resistance in wheat. In K.J. Leonard, W.R. Bushnell (eds). Fusarium Head Blight of wheat and barley. APS Press, St. Paul, Minnesota, USA. pp. 184-210.

Engle, J.S., Lipps, P.E., Mills, D. 2003. Fusarium head blight severity scale for winter wheat. Published online by the Ohio State University, Bulletin AC-48-03, Extension Factsheet, Columbus, USA.

Federer, W.T. 1961. Augmented designs with one-way elimination of heterogeneity. Biometrics 17:447-473.

Figlan, S., Baloyi, T.A., Hlongoane, T., Terefe, T.G., Shimelis, H., Tsilo, T.J. 2017. Adult plant resistance of selected Kenyan wheat cultivars to leaf rust and stem rust diseases. Cereal Res. Commun. 45:68-82.

Fuentes, R.G., Mickelson, H.R., Busch, R.H., Dill-Macky, R., Evans, C.K., Thompson, W.G., Wiersma, J.V., Xie, W., Dong, Y., Anderson, J.A. 2005. Resource allocation and cultivar stability in breeding for Fusarium head blight resistance in spring wheat. Crop Sci. 45:1965-1972.

Gelderblom, W.C.A., Shephard, G.S., Rheeder, J.P., Sathe, S.K., Ghiasi, A., Motarjemi, Y. 2014. Edible nuts, oilseeds and legumes. In: Motarjemi, Y., Lelieveld, H. (eds). Food safety management: a practical guide for the food industry. Elsevier. The Netherlands. pp. 301-324.

Goswami, R.S., Kistler, H.C. 2004. Heading for disaster: Fusarium graminearum on cereal crops. Mol. Plant Pathol. 5(6):515-525.

He, X., Singh, P.K., Duveiller, E., Schlang, N., Dreisigacker, S., Singh, R.P. 2013. Identification and characterization of international Fusarium head blight screening nurseries of wheat at CIMMYT, Mexico. Eur. J. Plant Pathol. 136:123-134.

Lilleboe, D. 2011. Fusarium head blight in 2011: An overview. http://www.scabusa.org/pdfs/USWBSIArticle_2011-Update_9-29-11.pdf (Accessed 15 February 2016).

Lin, F., Xue, S.L., Zhang, Z.Z., Zhang, C.Q., Kong, Z.X., Yao, G.Q., Tian, D.G., Zhu, H.L., Li, C.J., Cao, Y., Wei, J.B. 2006. Mapping QTL associated with resistance to Fusarium head blight in the Nanda2419× Wangshuibai population. II: Type I resistance. Theor. Appl. Genet. 112(3):528-535.

Lu, Q., Lillemo, M., Skinnes, H., He, X., Shi, J., Ji, F., Dong, Y., Bjørnstad, Å. 2013. Anther extrusion and plant height are associated with Type I resistance to Fusarium head blight in bread wheat line 'Shanghai-3/ Catbird'. Theor. Appl. Genet. 126(2):317-334.

Mesterházy, Á., Bartók, T., Mirocha, C.G., Komoroczy, R. 1999. Nature of wheat resistance to Fusarium head blight and the role of deoxynivalenol for breeding. Plant Breeding 11(2):97-110.

Mesterházy, Á., Buerstmayr, H., Tóth, B., Lehoczki-Krsjak, S., Szabó-Hevér, Á., Lemmens, M. 2007. An improved strategy for breeding FHB resistant wheat must include type I resistance. In Proc. of the 5th Canadian Workshop on Fusarium Head Blight. Delta Winnipeg, Canada. pp. 27-30.

Misihairabgwi, J.M., Ezekiel, C.N., Sulyok, M., Shephard, G.S., Krska, R. 2017. Mycotoxin contamination of foods in Southern Africa: A 10-year review (2007-2016). Crit. Rev. Food Sci. Nutr. pp. 1-16.

Nganje, W.E., Bangsund, D.A., Leistritz, F.L., Wilson, W.W., Tiapo, N.M. 2004. Regional economic impacts of Fusarium head blight in wheat and barley. Rev. Agric. Econ. 26(3):332-347.

Niwa, S., Kubo, K., Lewis, J., Kikuchi, R., Alagu, M., Ban, T. 2014. Variations for Fusarium head blight resistance associated with genomic diversity in different sources of the resistant wheat cultivar 'Sumai 3'. Breeding Sci. 64:90-96. 
Osman, M., He, X., Singh, R.P., Duveiller, E., Lillemo, M., Pereyra, S.A., Westerdijk-Hoks, I., Kurushima, M., Yau, S., Benedettelli, S., Singh, P.K. 2015. Phenotypic and genotypic characterization of CIMMYT's $15^{\text {th }}$ International Fusarium head blight screening nursery of wheat. Euphytica 205:521-537.

Palacios, S.A., Erazo, J.G., Ciasca, B., Lattanzio, V.M., Reynoso, M.M., Farnochi, M.C., Torres, A.M. 2017 a. Occurrence of deoxynivalenol and deoxynivalenol-3-glucoside in durum wheat from Argentina. Food Chem. 230:728-734.

Palacios, S.A., Merlera, G.G., Erazo, J., Reynoso, M.M., Farnochi, M.C., Torres, A.M. 2017b. Trichothecene genotype and genetic variability of Fusarium graminearum and F. cerealis isolated from durum wheat in Argentina. Eur. J. of Plant Pathol. 149(4):969-981.

Rieseberg, L.H., Widmer, A., Arntz, A.M., Burke, J.M. 2003. The genetic architecture necessary for transgressive segregation is common in both natural and domesticated populations. Philos. T. Roy. Soc. B 358:11411147.

Rudd, J.C., Horsley, R.D., McKendry, A.L., Elias, E.M. 2001. Host plant resistance genes for Fusarium head blight: sources, mechanisms, and utility in conventional breeding systems. Crop Sci. 41:620-627.

Shah, D.A., De Wolf, E.D., Paul, P.A., Madden, L.V. 2014. Predicting Fusarium head blight epidemics with boosted regression trees. Phytopathology 104:702-714.

Shephard, G., Berthiller, F., Dorner, J., Krska, R., Lombaert, G., Malone, B., Maragos, C., Sabino, M., Solfrizzo, M., Trucksess, M., van Egmond, H. 2009. Developments in mycotoxin analysis: an update for 2007-2008. World Mycotoxin J. 2(1):3-21.

Singh, R.P., Rajaram, S. 2015. Breeding for disease resistance in wheat. http://www.fao.org/docrep/006/ y4011e/y4011e0b.html. (Accessed 01 September 2016).

SAGL (South African Grain Laboratories). 2018. http://www.sagl.co.za/Portals/0/Wheat\%20Crop\%20 2015\%202016/PAGE\%2058-59.pdf. Accessed 12 August 2018.

Schumann, G.L., D’Arcy, C.J. 2006. Essential plant pathology. APS Press Minnesota, USA, pp. 10-12.

Spanic, V., Lemmens, M., Drezner, G. 2013. Variability in components of Fusarium head blight resistance among wheat genotypes. Cereal Res. Commun. 41(3):420-430.

Szabó-Hevér, A., Lehoczki-Krsjak, S., Varga, M., Purnhauser, L., Pauk, J., Lantos, C., Mesterházy, A. 2014. Differential influence of QTL linked to Fusarium head blight, Fusarium-damaged kernel, deoxynivalenol contents and associated morphological traits in a Frontana-derived wheat population. Euphytica 200:9-26.

Tunali, B., Obanor, F., Erginbaş, G., Westecott, R.A., Nicol, J., Chakraborty, S. 2012. Fitness of three Fusarium pathogens of wheat. FEMS Microbiol. Ecol. 81(3):596-609.

Varga, E., Wiesenberger, G., Hametner, C., Ward, T.J., Dong, Y., Schöfbeck, D., McCormick, S., Broz, K., Stückler, R., Schuhmacher, R., Krska, R. 2015. New tricks of an old enemy: isolates of Fusarium graminearum produce a type A trichothecene mycotoxin. Environ. Microbiol. 17(8):2588-2600.

Wilde, F., Korzun, V., Ebmeyer, E., Geiger, H.H., Miedaner, T. 2007. Comparison of phenotypic and markerbased selection for Fusarium head blight resistance and DON content in spring wheat. Mol. Breeding 19(4):357-370.

Yi, X., Cheng, J., Jiang, Z., Hu, W., Bie, T., Gao, D., Li, D., Wu, R., Li, Y., Chen, S., Cheng, X. 2018. Genetic analysis of fusarium head blight resistance in CIMMYT bread wheat line C615 using traditional and conditional QTL mapping. Front. Plant Sci. 9:573.

Zain, M.E. 2012. Impact of mycotoxins on humans and animals. J. Saudi Chem. Soc. 15:129-144.

\section{Electronic Supplementary Material (ESM)}

Electronic Supplementary Material (ESM) associated with this article can be found at the website of CRC at http://www.akademiai.com/content/120427/

Electronic Supplementary Table S1. Weather conditions of the four testing environments during the study period 